\title{
Evaluation of fracture toughness of epoxy polymer composite incorporating micro/nano silica, rubber and CNTs
}

\author{
Ronaldo Câmara Cozza ${ }^{1 *}$ (1) and Vikas Verma² \\ ${ }^{1}$ Departamento de Engenharia Mecânica, Centro Universitário da Fundação Educacional Inaciana "Padre \\ Sabóia de Medeiros" - FEI, São Bernardo do Campo, SP, Brasil \\ ${ }^{2}$ Thermochemistry of Materials SRC, National University of Science and Technology - NUST/MISiS, \\ Moscow, Russia \\ *rcamara@fei.edu.br
}

\begin{abstract}
In engineering applications, fracture toughness is an essential requirement that determines the life of a material. Epoxy polymers are widely used in fibre-reinforced composite materials. Due to their structural efficiency and durability, the use of adhesive and composite materials based on epoxy polymers is widespread in aerospace and automobile industries. In this paper fracture toughness of hybrid epoxy polymer composite with addition of nano/micro figures of silica, rubber and carbon nano tubes (CNTs) is evaluated. It is observed that silica addition promoted nano toughening effect with plastically deformation capability in epoxies. Rubber and multi walled CNTs increased the toughness with negligible reduction in stiffness in epoxies. Future research emphasis can be laid on crucial understanding of stress transfer mechanisms and interfacial bond strength between nano particles - epoxy system and on nanofillers modified epoxies as matrices or interleafs for carbon or glass fiber composites to increase the interlaminar delamination toughness.
\end{abstract}

Keywords: CNT, epoxy, rubber, silica.

How to cite: Cozza, R. C., \& Verma, V. (2020). Evaluation of fracture toughness of epoxy polymer composite incorporating micro/nano silica, rubber and CNTs. Polímeros: Ciência e Tecnologia, 30(3), e2020030. https://doi. org/10.1590/0104-1428.05720

\section{Introduction}

Epoxy polymers are widely used in fibre-reinforced composite materials ${ }^{[1]}$. The use of adhesive and composite materials based on epoxy polymers is widespread in the aerospace, automobile and wind-energy industries due to their structural efficiency ${ }^{[2]}$. Their outstanding temperature resistance and durability to weathering, fuel, de-icing fluids, etc. leads to them invariably being the preferred materials, compared to acrylics and polyurethanes, for external aerospace applications. Furthermore, their insulating properties, good temperature resistance and ease of processing also allow epoxy polymers to be used extensively in the electronics and electrical components ${ }^{[2]}$. However the limitations of epoxies as structural materials are due to their poor resistance to the initiation and growth of cracks. Thus, improvements in their fracture performance are highly sought after by industry. However there have been several researches on thermoplastic and thermoset polymer to overcome these drawbacks by modifying epoxy resins with integration of various nanofillers as a second microphase, for advanced composite applications ${ }^{[2,3]}$. An epoxy polymers based composite material has numerous advantages as it offers excellent mechanical properties and thermal stability ${ }^{[3]}$. Hybrid polymer composites (HPC) are one of the recent developments to reduce the cost of expensive composites containing reinforcements like carbon fiber by incorporating a proportion of cheaper, low-quality fibers such as glass, textile, natural fibers, and nano figures like (silica, rubber,
CNT, clay, graphene). A lot of work has been carried in past to improve the fracture toughness of a polymer composite. Most of the reviewed data in this paper are based on the classification of incorporating different fibers, CNTs and micro/nano size silica, rubber particles in the epoxy resin as shown in schematic diagram Figure 1.

Following the above brief introduction, Section 2 presents an overview of fracture toughness evaluation of epoxy resin modified with silica nano and micro particles; Section 3 is concerned with fracture toughness behaviors of epoxy resin modified by rubber particles, Section 4 deals with the effect of fracture toughness of an epoxy resin modified by different CNTs with varying wt.\%. Section 5 describes the recent development achieved towards fracture toughness evaluation of different hybrid polymer composite. Section 6 concludes with research gap to address for some unattended problem in hybrid polymer composite.

\section{Overview of Fracture Toughness Evaluation of Epoxy Resin Modified with Silica Nano and Micro Particles}

The use of silicate-based filler in polymer composite has been a great interest for research as it improves the mechanical properties, especially fracture toughness of epoxies $^{[1,2]}$. 


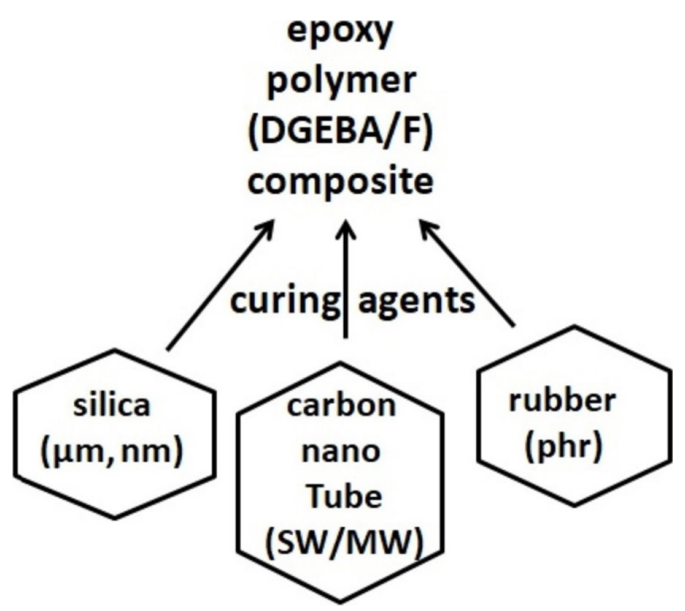

Figure 1. Materials used for toughening of epoxies.

Hsieh et al. ${ }^{[1]}$ used four different epoxy polymers to modify with silica (10-20 wt.\%) nano particles. They are anhydride-cured DGEBA (diglycidyl ether of bis-phenol A), polyether-amine cured DGEBA/F (diglycidyl ether of bisphenol F), and polyether-amine cured DGEBA and amine-cured TGMDA (tetraglycidylmethylenedianiline). Single-edge notch-bend (SENB) and double-notched four point specimen have been conducted to observe the toughness differences. Toughest material identified was polyether-amine cured DGEBA/F epoxy posses low transition temperatures $\left(T_{G}\right)$ and high molecular weight $\left(M_{C}\right)$. AFM phase images of unmodified and epoxy polymers containing the silica nanoparticles, are shown in Figure 2a, b. Unmodified epoxy polymers showed as homogeneous thermoset polymers whereas epoxy polymers having silica nanoparticles, exhibited a very well-dispersed phase of silica nanoparticles, with no indications of agglomeration.

Predominant toughening mechanisms in epoxy polymers containing silica nanoparticles were identified as localized shear bands initiated by the stress concentrations around the periphery of the silica nanoparticles with debonding features of the silica nanoparticles followed by subsequent plastic void growth of the epoxy polymer. Bray et al. ${ }^{[2]}$ modified the piperidine-cured epoxy polymer by adding silica nano particles of varying diameter. Toughness increased steadily as the concentration of silica-nano particles was increased with no significant effect of particle size being observed. The toughening mechanisms were identified as the formation of localized shear-band yielding in the epoxy matrix polymer initiated by the silica nanoparticles, and debonding of the silica nanoparticles followed by plastic void growth of the epoxy matrix polymer as shown in Figure $3 a, b$.

It was observed that incorporation of nanomaterials in the polymer matrix maintaining a homogeneous dispersion and good adhesion is considered to be a highly effective in improving the mechanical properties of resins ${ }^{[3]}$. Finite element analysis can also be used to estimate the fracture behavior of hybrid polymer composite (HPC) $)^{[4]}$. Epoxyfunctionalised toughening particles results in superior tensile, compressive and impact properties which can be tested fracture toughness testing methods like indentation strength method (IS), the single edge notched beam (SENB) and the Chevron notched beam method $(\mathrm{CN})^{[5,6]}$. The "nano" effects of silica $(<25$ vol. $\%$ ) or rubber $(>10 \mathrm{wt} . \%)$ nanoparticles in toughening epoxy resin are confirmed by Marouf et al. ${ }^{[7]}$.

Dittanet et al. ${ }^{[8]}$ studied the effect of silica nanoparticle content and particle size on glass transition temperature $\left(T_{G}\right)$ coefficient of thermal expansion (CTE), Young's modulus $(E)$, yield stress $(s)$, fracture energy $\left(G_{I C}\right)$ and toughness $\left(K_{I C}\right)$. The addition of silica nanoparticles does not have significant effect on $T_{G}$ or yield stress of epoxy resin. The CTE (coefficient of thermal expansion) values of nano silica filled epoxies were found to decrease with increasing silica nanoparticle content. The young's modulus was found to be significantly improved with the addition of silica nanoparticles \& increased with increasing fiber content. Particle size did not exhibit any effect on the young's modulus. The fracture toughness $\&$ fracture energy showed significant improvement with the addition of silica nanoparticles and increasing with increasing filler material. Observation of the fracture surfaces showed evidence of debonding of silica nanoparticles, matrix void growth, and matrix shear banding, which are credited for the increases in toughness for nano silica-filled epoxy systems. Dittanet et al. ${ }^{\left[{ }^{[9]}\right.}$ formulated the epoxy mixtures of two different size distributions of silica-based particles (micron-size and nanometer-size) for possible synergistic toughening effects. The influence of bimodal particle size mixture and silica particle content on the glass transition temperature, coefficient of thermal expansion, Young's modulus, yield stress, and fracture toughness, was investigated. Fracture toughness improved by approximately $30 \%$ when mixtures of microparticles and nanoparticles were used. The increased fracture energy found in bimodal systems is mainly due to the contribution from the plastic void growth mechanism, by the silica nanoparticles, together with matrix shear banding. Johnsen et al. ${ }^{[10]}$ examined the toughening mechanisms of epoxy/nanosilica composites using single-edge notch bend (SENB) specimens. Fracture energy increased from $103 \mathrm{~J} /$ $\mathrm{m}^{2}$ to $291 \mathrm{~J} / \mathrm{m}^{2}$ at $4.0 \mathrm{wt}$.\% loading, $182 \%$ increment. Further increase in nano filler loading by $7.8 \mathrm{wt} . \%$ increased the fracture toughness performance. SEM studies showed the presence of debonding and plastic void growth as contributing factors for the enhancement of fracture toughness. Blackman et al. ${ }^{[1]}$ investigated the fracture and fatigue performance of nanosilica modified epoxy polymers. Interesting observations were made by the authors when the loading of nanosilica was increased progressively. An increment of $51.7 \%$ in fracture toughness was observed in comparison with the neat epoxy. Microscopic studies were performed to analyse the nature of such enhancement. Debonding of nanosilica and plastic void growth were the factors that essentially contributed to the toughening mechanisms of the nanocomposite. The effects of particle size and volume fraction on the fracture toughness of epoxy composites filled with spherical silica particles were investigated by Adachi et al. ${ }^{[12]}$ and found that the fracture toughness increased drastically as the volume fraction increased and the particle diameters decreased. Nano and micron-silica particles bidispersed epoxy composites showed that the composites had a lower fragility with higher strength and fracture toughness with increase in nanoparticles ${ }^{[13]}$. Glass transition temperature and fragility are found useful parameters for estimating 

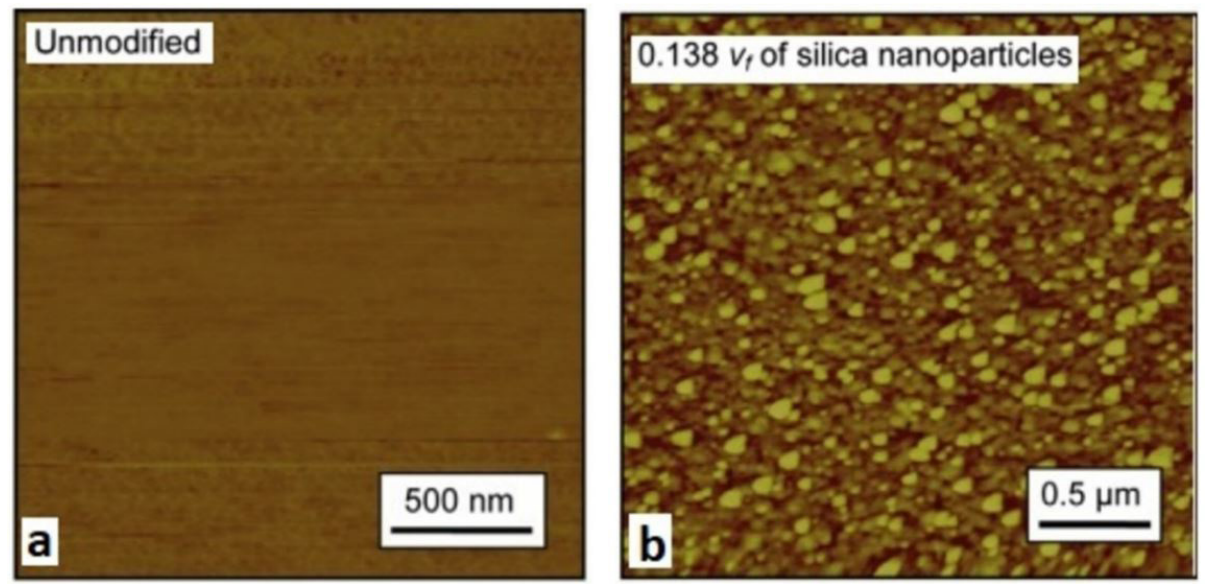

Figure 2. AFM phase images of the polyether-amine cured DGEBA epoxy polymer: (a) Unmodified and (b) $0.138 \mathrm{v}_{F}$ of silica nanoparticles ${ }^{[1]}$.
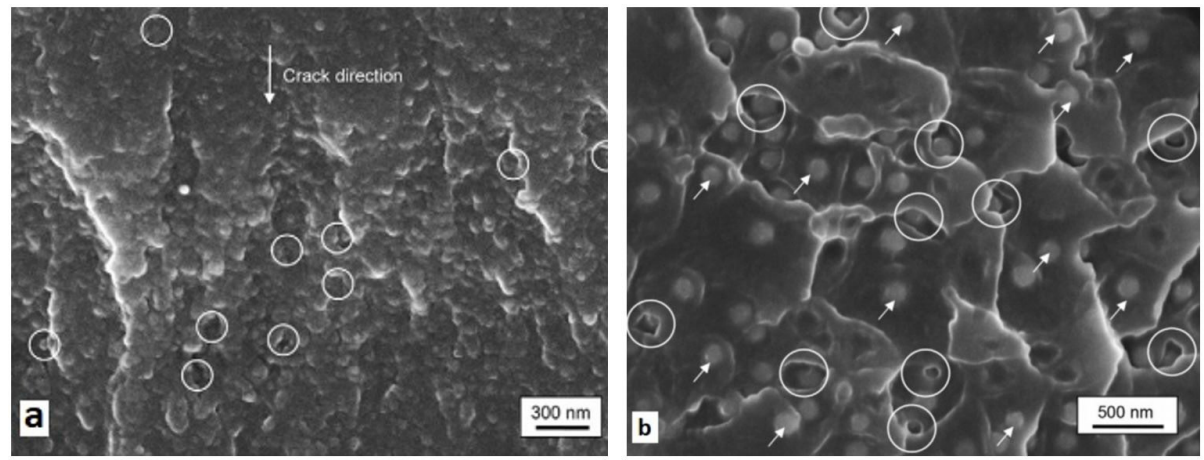

Figure 3. (a) and (b) High resolution SEM images of the fracture surfaces for the epoxy polymers containing silica nanoparticles ${ }^{[1,2]}$.

the fracture toughness of the silica particulate-filled epoxy composites $^{[13,14]}$. Apart from mechanical properties epoxy resins in the uncured state have relatively high viscosities ${ }^{[15]}$. The viscosity of the uncured mixture must be sufficiently low to permit the evacuation of air bubbles. Fracture mechanics of the epoxy composites revealed that crack growth depends upon the intensity of stress at the tip of the $\operatorname{crack}^{[16]}$. Effect of particle size on the fracture behaviour of cured epoxy resin filled with spherical silica particles showed that the main crack propagation was hampered by large particles and a damage zone was formed at the main crack tip region in the large particle filled resin due to crack diversion and debonding of particle/matrix interfaces ${ }^{[17,18]}$. It was found that fracture surface morphology in unfilled and particulatefilled epoxy resins under static loading was governed by slow, sub-critical crack growth manifested by resin-particle debonding ${ }^{[19]}$. Unfilled resins exhibited unstable (or stickslip) crack propagation at low and high cross-head speeds whereas filled resins showed stable crack propagation at all speeds in double torsion test technique ${ }^{[20]}$. The research conducted on improvement of fracture toughness of epoxy composite incorporated with nano or micro-sized silica particles resulted in improvement of mechanical properties of epoxy resins such as elastic modulus, hardness, impact resistance and fracture toughness. Epoxy-nanocomposite resins filled with $12 \mathrm{~nm}$ spherical silica particles decreased in cure and glass transition temperature (for loadings of $10 \mathrm{wt} . \%$ and above) with increased silica loading ${ }^{[21]}$. Liang and Pearson ${ }^{[22]}$ in their study found that no significant differences in fracture behavior were observed between the epoxies filled with different nano silica $(20 \mathrm{~nm}$ or $80 \mathrm{~nm}$ NS particles). Effect of silica nanoparticles on toughness of two epoxy systems cured by Jeffamine D230 (J230) and 4,40-diaminodiphenyl sulfone (DDS), improved the toughness of J230-cured epoxy from 0.73 to $1.68 \mathrm{MPa}^{1 / 2}$, and for the other system improved from 0.51 to $0.82 \mathrm{MPa}$. $\mathrm{m}^{1 / 2[23]}$. Fracture behaviours of nanosilica filled bisphenol-F epoxy resin investigated at ambient and higher temperatures showed improved elastic modulus, microhardness, impact resistance and fracture toughness of epoxy matrix with increasing nanoparticle volume content as the nanoparticles were almost homogeneously dispersed in epoxy matrix ${ }^{[24]}$. It was also shown that addition of $5 \mathrm{vol} \%$. silica-nanoparticles could improve the stiffness and the toughness of an epoxy resin at the same time and the nano-reinforced material behaved more ductile and showed a bigger yielding than the pure epoxy ${ }^{[25]}$. Zhang et al. ${ }^{[26]}$ found that the static/ dynamic modulus, microhardness, and fracture toughness of the nanocomposites enhanced with increasing silica content up to 14 vol.\% (23 wt.\%) due to homogeneously distributed nanoparticles which improved both the stiffness and toughness of the epoxy. Epoxy-silica nanocomposites 
produced by dispersing silica-organosol particles in TGDDM/ DDS resin mixtures resulted an increased interfacial adhesion which improved fracture properties ${ }^{[27]}$. Organophilic layered silicates (OLS), modified by means of cation exchange, were added in amounts of 5-15 wt.\% to vinylester (VE)/ epoxy (EP) hybrid resins which formed interpenetrating networks (IPN) after curing at $T=150{ }^{\circ} \mathrm{C}$, doubled the fracture energy of the resins with 5 wt. $\%$ OLS ${ }^{[28]}$. The type of the organic cation modification of the OLS had no effect on morphology or toughness which was attributed to the coarse dispersion of the OLS and its encapsulation by the EP phase in the VE/EP hybrid resin ${ }^{[28]}$. Fu et al. ${ }^{[29]}$ provided a review on the effects of particle size, interfacial strength, and filler loading on the elastic modulus, strength, fracture toughness, and impact behaviors of polymer composites containing nano/micro-size particulates. Rosso et al. ${ }^{[25]}$ employed the well-dispersed silica nanocomposites for tensile and fracture tests, indicating that the addition of 5 vol. $\%$ silica nanoparticles could improve the stiffness and fracture energy to $20 \%$ and $140 \%$, respectively. Guo and $\mathrm{Li}^{[30]}$ performed compressive loading on the $\mathrm{SiO}_{2} /$ epoxy nano composites under different loading rates, revealing that the compressive strength of the composites with silica nanoparticles is higher than pure epoxy at higher strain rates; nevertheless, there is no clear connection between the compressive strength and the nanoparticle contents at lower strain rates.

Summarising, the use of silica nanoparticles as an effective toughening agent for epoxies which can plastically deform and the nano toughening effect is confirmed in silica/epoxy nano -composites. Crack growth originates from debonding of silica nanoparticles which promote matrix plasticity via shear yielding and void growth as the main energy dissipation mechanisms. The incorporation of silica particles uniformly dispersed in the matrix as seen in the micrographs shown and stated by different researchers discussed above of the processed epoxy composite, either nano-size or micro-size, into neat epoxies increases fracture toughness, $K_{I C}$ and normalized fracture energy, $G_{I C}$. Nanosize fillers are more effective tougheners than micro-size fillers over the full range of filler loading up to $60 \mathrm{wt} . \%$. Table 1 summarises the published reports on silica particlefilled epoxies to evaluate the influence of these fillers on increasing fracture toughness.

\section{Overview of Fracture Toughness Evaluation of Epoxy Resin Modified with Rubber}

Several methods have been proposed to improve the fracture toughness of epoxy resins and addition of suitable rubber before epoxy resin curing is claimed to be a successful routine ${ }^{[31]}$. Chikhi et al. ${ }^{[31]}$ worked on liquid amine-terminated butadiene acrylonitrile (ATBN) copolymers containing 16\% acrylonitrile at different contents to improve the toughness of DGEBA epoxy resin using polyaminoimidazoline as a curing agent and post cured at $120^{\circ} \mathrm{C}$. In modified epoxy resin, all reactivity characteristics (gel time and temperature, cure time and exotherm peak) were decreased. Where as a 3 -fold increase in Izod IS was obtained by just adding $12.5 \mathrm{phr}$ ATBN compared to the unfilled resin. Addition of ATBN, the Izod IS increased drastically from 0.85 to $2.86 \mathrm{~kJ} / \mathrm{m}^{2}$ and from 4.19 to $14.26 \mathrm{~kJ} / \mathrm{m}^{2}$ for notched and unnotched specimens respectively while $K_{I C}$ varies from 0.91 to $1.49 \mathrm{MPa}^{1 / 2}$. Concerning the adhesive properties, the tensile shear strength (TSS) increased from 9.14 to $15.96 \mathrm{MPa}$ just by adding $5 \mathrm{phr}$ ATBN. Finally SEM analysis suggested that rubber particles cavitation and localized plastic shear yielding induced by the presence of the dispersed rubber particles within the epoxy matrix as the prevailing toughening mechanism. Zhao et al. ${ }^{[32]}$ worked on enhancement in tensile strength and

Table 1. Summary on Silica/Epoxy composite.

\begin{tabular}{|c|c|c|c|c|c|c|}
\hline $\begin{array}{l}\text { Type of Epoxy } \\
\text { Polymers }\end{array}$ & $\begin{array}{l}\text { Modifier } \\
\mathrm{SiO}_{2} \text { size } \\
(\mathrm{nm})\end{array}$ & $\begin{array}{c}\mathrm{SiO}_{2} \\
\text { Addition }\end{array}$ & $\begin{array}{c}\text { Fracture } \\
\text { toughness } \\
\left(\mathrm{MPa.m}^{1 / 2}\right)\end{array}$ & $\begin{array}{l}\text { Fracture energy } \\
\qquad\left(\mathrm{J} / \mathbf{m}^{2}\right)\end{array}$ & Curing Agent & Ref. \\
\hline $\begin{array}{c}\text { DGEBA } \\
\text { DGEBA/F } \\
\text { Polyether DGEBA } \\
\text { TGMDA }\end{array}$ & - & $0-20$ wt. $\%$ & $\begin{array}{l}1.45 \pm 0.12, \\
\text { highest for } \\
\text { polyether DGEBA } \\
\text { at } 0.138 \text { volume } \\
\text { fraction silica }\end{array}$ & $\begin{array}{c}616 \pm 109, \text { highest } \\
\text { for polyether } \\
\text { DGEBA at } 0.138 \\
\text { volume fraction } \\
\text { silica }\end{array}$ & $\begin{array}{l}\text { Accelerated } \\
\text { methylhexahy } \\
\text { drophthalic acid } \\
\text { anhydride }\end{array}$ & Hsieh et al. ${ }^{[1]}$ \\
\hline DGEBA & $\begin{array}{c}\text { Unmodified } \\
23 \\
74 \\
170\end{array}$ & 30 vol. $\%$ & $\begin{array}{l}1.11 \pm 0.06 \\
2.52 \pm 0.11 \\
2.89 \pm 0.11 \\
2.65 \pm 0.06\end{array}$ & $\begin{array}{r}303 \pm 14 \\
973 \pm 17 \\
1264 \pm 14 \\
1030 \pm 08\end{array}$ & Piperidine & $\begin{array}{l}\text { Dittanet and } \\
\text { Pearson }^{[8]}\end{array}$ \\
\hline DGEBA & $\begin{array}{c}\text { Neat resin } \\
42 \mu \mathrm{m}^{+} \\
23 \mathrm{~nm} \\
42 \mu \mathrm{m}^{+} \\
74 \mathrm{~nm} \\
42 \mu \mathrm{m}^{+} \\
170 \mathrm{~nm}\end{array}$ & 10 vol. $\%$ & $\begin{array}{l}1.07 \pm 0.1 \\
1.96 \pm 0.15\end{array}$ & $\begin{array}{l}280 \pm 20 \\
760 \pm 10 \\
740 \pm 80 \\
750 \pm 10\end{array}$ & 5 phr piperidine & $\begin{array}{l}\text { Dittanet and } \\
\text { Pearson }^{[9]}\end{array}$ \\
\hline DGEBA & $20 \mathrm{~nm}$ & 13 vol. $\%$ & $0.59-1.42$ & $100-460$ & $\begin{array}{l}\text { Methylhexahydrophthalic } \\
\text { acid anhydride (HE600) }\end{array}$ & Johnsen et al. ${ }^{[10]}$ \\
\hline DGEBF & $90 \mathrm{~nm}$ & $0-7 \%$ & $\begin{array}{l}\text { Increase in strain } \\
\text { rate }\end{array}$ & - & $\begin{array}{c}\text { Poly(propyleneglycol)- } \\
\text { diglycidyl ether } \\
\text { (PPGDE) }\end{array}$ & Guo and $\mathrm{Li}^{[30]}$ \\
\hline
\end{tabular}


fracture toughness at $77 \mathrm{~K}$ of diglycidyl ether of bisphenol-F (DGEBF) epoxy using diethyl toluene diamine (DETD) as curing agent and carboxylic nitrile-butadiene nano rubber (NR) particles. Dispersion of NR in the cured epoxy samples is shown in Figure 4. It was found NR dispersion throughout the epoxy matrix with no agglomeration ${ }^{[32]}$.

The tensile strength is increased compared with that of the pure epoxy. The SENB test is used to determine the $K_{I C}$. Fracture toughness $\left(K_{I C}\right)$ is enhanced by $48.3 \%$ at $15 \mathrm{phr}$ NR compared with that of the pure epoxy. Moreover, the comparison of mechanical properties between $77 \mathrm{~K}$ and room temperature indicated that the tensile strength, young's modulus and fracture toughness at $77 \mathrm{~K}$ are higher than those at room temperature with reduced young's modulus of epoxy resins. Chen and Taylor ${ }^{[33]}$ investigated the fracture toughness and mechanical properties of an anhydride-cured diglycidylether of bisphenol-A(DGEBA)

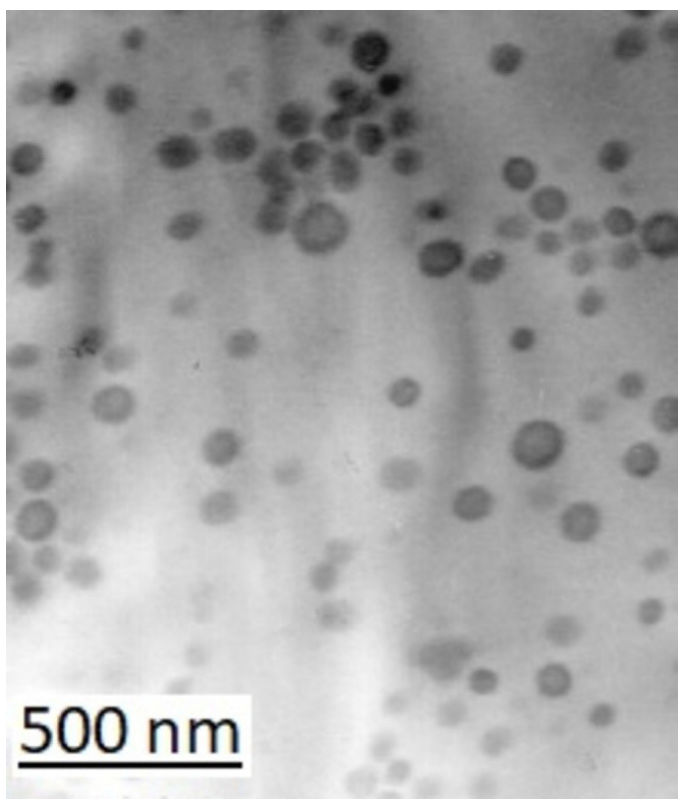

Figure 4. Dispersion of NR particles in the NR-epoxy blends ${ }^{[13]}$.

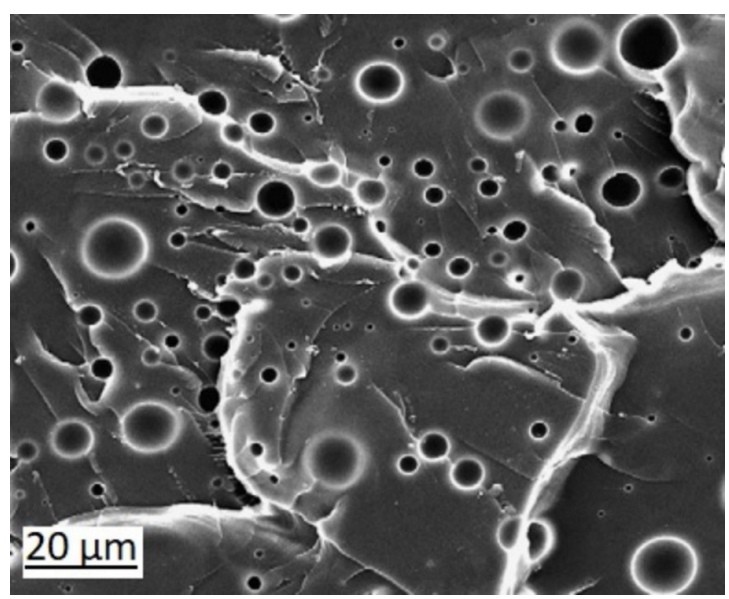

Figure 5. SEM micrograph of rubber-modified epoxy showing stress-whitened zone ${ }^{[51]}$. epoxy polymer modified with poly(methyl methacrylate)-bpoly(butylacrylate)-b-poly(methyl methacrylate) (MAM). These triblock copolymers toughen the epoxy polymer significantly, with only slight reductions in the mechanical and thermal properties of the epoxy polymer. The maximum values of fracture toughness and fracture energy (1.22 MPa. $\mathrm{m}^{1 / 2}$ and $450 \mathrm{~J} / \mathrm{m}^{2}$, respectively) were measured which is an increase of 100 and $350 \%$, respectively, compared with the unmodified epoxy. Carboxyl terminated butadiene acrylonitrile rubber (CTBN), amine terminated butadiene acrylonitrile rubber (ATBN), epoxy terminated butadiene acrylonitrile (ETBN) and hydroxyl terminated poly butadiene liquid rubber (HTPB) have been used to enhance the fracture toughness of epoxy resins at room temperature (RT) where micro- sized rubber-modified epoxy resins showed enhanced fracture toughness with lowered strength ${ }^{[34-51]}$. SEM photograph of a fractured surfaces of $10 \mathrm{phr}$ rubbermodified epoxy (Figure 5) showed stress-whitened zone near the crack tip occurred due to micro-cavitations of rubber particles because of high hydrostatic stress beneath the blend crack tip ${ }^{[5]}$. Rubber modifiers are also used in the forms of reactive oligomers (e.g., carboxyl terminated butadiene acrylonitrile CTBN, amine terminated butadiene acrylonitrile ATBN, etc) ${ }^{[52]}$ enhance the fracture toughness of epoxies. the rubber nanoparticles in the form of spherical and wormlike micelles increase $K_{I C}$ monotonically. The microsize rubber particles (CTBN and ATBN) may impart higher, similar or lower $K_{I C}$ values in epoxies depending on the nature of epoxy and the rubber modifier, concentration of rubbery phase, and interface properties ${ }^{[52]}$.

Summarising, the toughening effects of rubber particles on epoxy resins, it is concluded that the micro-size and nano rubber particles (CTBN and ATBN) impart higher toughness in epoxies. Table 2 Summaries the published reports on rubber particle-filled epoxies to evaluate the influence of these fillers on increasing fracture toughness.

\section{Overview of Fracture Toughness Evaluation of Epoxy Resin Modified with Carbon Nano Tubes (CNTs)}

Carbon nano tubes (CNTs) are generally considered as one of the potential fillers to improve the mechanical properties of polymer matrices ${ }^{[3-55]}$.

Ayatollahi et al ${ }^{[53]}$ had investigated the effects of MWCNT as nanofillers on epoxy matrix under bending and shear loading conditions. Shear loading was found more effective in comparison to normal loading. Single-edge notch bend specimen (SENB) was used for this study. Fracture toughness increased with $0.1 \mathrm{wt} . \%$ to $0.5 \mathrm{wt} . \%$ MWCNT addition resulting in $30 \%$ higher than that of the neat epoxy. Hsieh et al. ${ }^{[54]}$ used Multi-walled carbon nanotubes, with a typical length of $140 \mu \mathrm{m}$ and a diameter of $120 \mathrm{~nm}$, to modify anhydride-cured epoxy polymer. TOM images revealed that the MWCNTs were agglomerated in the epoxy polymer at all the concentrations employed (Figure 6).

The modulus, fracture energy and the fatigue performance of the modified polymers have been investigated. The addition of nanotubes increased the modulus of the epoxy, fracture energy from 133 to $223 \mathrm{~J} / \mathrm{m}^{2}$ and threshold strain energy 
Table 2. Summary on Rubber/Epoxy composite.

\begin{tabular}{|c|c|c|c|c|c|}
\hline Type of Epoxy & Modifier rubber & $\begin{array}{c}\text { Rubber Addition } \\
\text { (phr) }\end{array}$ & $\begin{array}{l}\text { Fracture toughness } \\
\left(\mathrm{MPa} \cdot \mathrm{m}^{1 / 2}\right)\end{array}$ & Curing Agent & Ref. \\
\hline DGEBA & $\begin{array}{l}\text { Amine terminated } \\
\text { butadiene } \\
\text { acrylonitrile rubber } \\
\text { (ATBN) }\end{array}$ & $5-20$ & 0.91 to 1.49 & Polyaminoimidazoline & Chikhi et al. ${ }^{[31]}$ \\
\hline DGEBF & $\begin{array}{l}\text { Carboxylic nitrile- } \\
\text { butadiene nano }\end{array}$ & 15 & $\begin{array}{c}48.3 \% \text { increment } \\
\text { at } 77 \mathrm{~K}\end{array}$ & $\begin{array}{l}\text { Diethyl toluene diamine } \\
\text { (DETD) }\end{array}$ & Zhao et al..$^{[32]}$ \\
\hline DGEBA & $\begin{array}{l}\text { (M22N, M52N, } \\
\text { M52)* }\end{array}$ & 12 wt. $\%$ & 1.22 & $\begin{array}{l}\text { Methylhexahydrophthalic } \\
\text { acid anhydride }\end{array}$ & $\begin{array}{l}\text { Chen and } \\
\text { Taylor }^{[33]}\end{array}$ \\
\hline DGEBA & $\begin{array}{c}\text { Epoxy terminated } \\
\text { butadiene } \\
\text { acrylonitrile (ETBN) } \\
\& \text { ATBN }\end{array}$ & $0-15$ & $1-1.65$ & $\begin{array}{l}\text { Trimethylene glycol di-p- } \\
\text { aminobenzoate (TMAB) }\end{array}$ & Hwang et al. ${ }^{[47]}$ \\
\hline DGEBA & $\begin{array}{l}\text { Hydroxyl terminated } \\
\text { polybutadiene liquid } \\
\text { rubber (HTPB) }\end{array}$ & $0-20$ & 1.5 & $\begin{array}{l}\text { Cyclic anhydride } \\
\text { (Hy906) }\end{array}$ & Thomas et al. ${ }^{[51]}$ \\
\hline
\end{tabular}

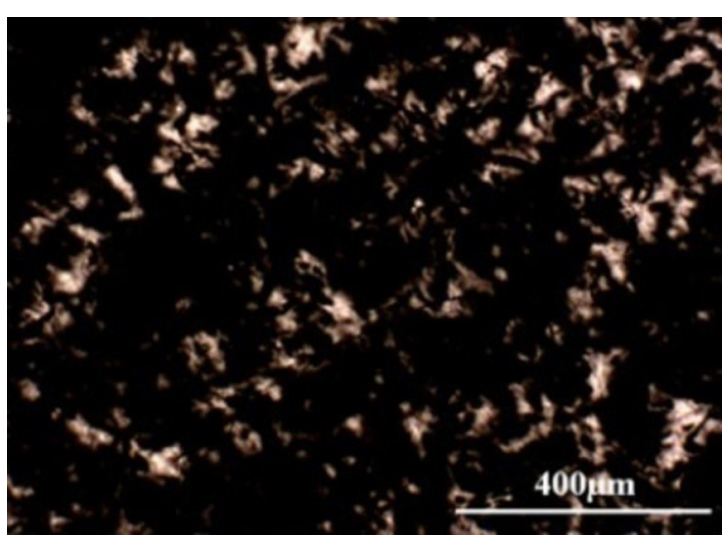

Figure 6. TOM images of the nanocomposites containing 0.5 wt.\% MWCNT ${ }^{[15]}$.

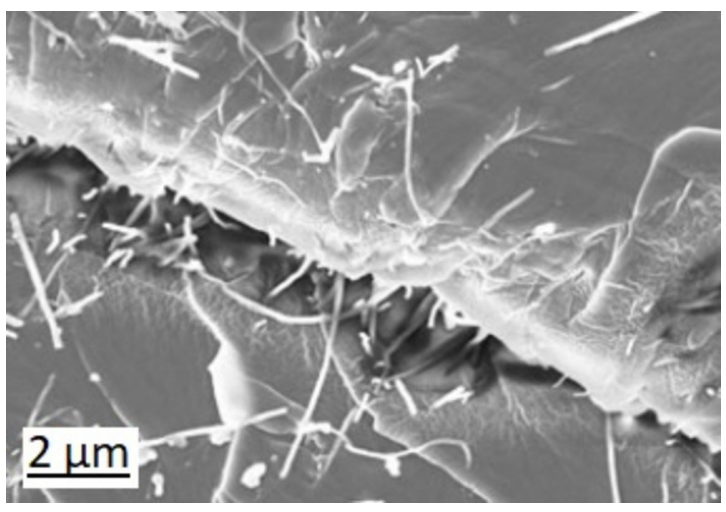

Figure 7. FEG-SEM image of the nanocomposite containing 0.5 wt. \% MWCNT showing nanotube bridging ${ }^{[15]}$.

release rate $G t h$, increased from 24 to $73 \mathrm{~J} / \mathrm{m}^{2}$ with $0.5 \mathrm{wt} . \%$ nanotubes addition. Electron microscopy of the fracture surfaces showed clear evidence of nanotube debonding and pull-out with void growth around the nanotubes, in both the fracture and fatigue tests. Examination of the fracture surfaces showed nano tube bridging and voids due to debonding between MWCNTs and the matrix followed by plastic deformation can also be observed - Figure 7 .

Gkikas et al. ${ }^{[55]}$ studied the effect of dispersion on MWCNT toughened epoxy. Single edge notch 3-point bending (SENB) was used to determine the toughness of the nanocomposite. At 0.5 wt.\% CNT reinforcement and the sonication power at full amplitude $(100 \%)$ for $1 \mathrm{~h}$ increased the toughness by $95 \%$. Further sonication for $2 \mathrm{~h}$ revealed a reduction in the fracture properties of the nanocomposite. The importance of the duration and amplitude of the sonication process for good dispersibility was highlighted. For nanocomposite with the same CNT loading, reducing the sonication power to half of the maximum amplitude (50\%) and increasing the time to $2 \mathrm{~h}$, increased the fracture toughness by $550 \%$ as compared to the neat epoxy. The investigated results on the mechanical and fracture toughness properties reported by various researchers, the properties of polymer composites are enhanced at very low CNTs loading. Most of the loading values gathered from the reviewed papers are approximately in the same range. Amongst all the CNTs, DWCNT had produced the highest stiffness nanocomposites when surface functionalization was carried out. The values of young's modulus presented for most of the MWCNTs nanocomposites were much lower in comparison with SWCNTs and DWCNTs ones. This effect was explained due to the difference in specific surface area (SSA). Optimizing the sonication power during mixing resulted in the highest value of Mode I fracture toughness $\left(1300 \mathrm{~J} / \mathrm{m}^{2}\right)$ as reported by Gkikas et al. ${ }^{[55]}$. Results concerning appropriate type as single-walled CNT (SWCNT), double-walled CNT (DWCNT), or multi-walled CNT (MWCNT) in epoxies showed that CNTs addition increased the tensile properties; hardness, impact resistance, and fracture toughness of epoxy resins as discussed below ${ }^{[37,56-85]}$. Compressive behavior of epoxy resin system with addition of different kind of nanoparticles revealed that carbon nanotubes increased compressive yield strength modestly at low strain rates, but there is a significant increase at high strain rate ${ }^{[57]}$. Single walled carbon nanotube (SWCNT) in a polymer matrix increased fracture behavior with increasing weight percentage of SWCNT ${ }^{[58]}$. Finite-element modelling had demonstrated that once one 
silica nanoparticle debonds then its nearest neighbours are shielded from the applied stress field, and hence may not debond ${ }^{[58]}$. Covalently functionalized nanotubes have been observed as particularly good additives for polymer reinforcement, allowing for an excellent stress-strain transfer between nanotubes and polymer matrix ${ }^{[00]}$. Generally, the structural toughness arising from conventional energy dissipation mechanisms has the potential to be much more significant in nanocomposites than in composites containing conventional micron-size fibers ${ }^{[62]}$ whereas uniform distribution of MWCNTs in the matrix and the formation of voids significantly affect the fracture and fatigue behavior of MWCNT-reinforced composites ${ }^{[56,63]}$. Gojny et al. ${ }^{[6]]}$ found that the mechanical properties of potential matrices of fibre-reinforced polymers (FRP), such as epoxy resins, were significantly increased by low contents of carbon nanotubes (CNT) (tensile strength, young's modulus and fracture toughness). The glass-fibre-reinforced polymers (GFRP) containing $0.3 \mathrm{wt} . \%$ amino-functionalised double-wall carbon nanotubes (DWCNT-NH2) exhibited significantly improved matrix-dominated properties (e.g., interlaminar shear strength) ${ }^{[66]}$. Enhanced dispersion and alignment of CNTs in polymer matrices improved by optimum physical blending, in situ polymerization and chemical functionalization led to improve mechanical, electric, thermal, electrochemical, optical and super-hydrophobic properties ${ }^{[67]}$. The alignment of CNTs could also be increased by ex situ alignment due to force, electrical and magnetic field-induced methods ${ }^{[67]}$. It was found that the tensile strength improved with the increase of MWCNTs addition, and as MWCNTs loading reached $8 \mathrm{wt} . \%$, the tensile strength reached the highest value of $69.7 \mathrm{MPa}^{[68]}$. Park et al. ${ }^{[69]}$ oxyfluorinated multi-walled carbon nanotubes (MWNTs) at different temperatures and it was found that surface fluorine and oxygen contents increased with increasing oxyfluorination temperature which led to an increase of surface polarity of the MWNTs, resulting in increasing $K_{I C}$ and impact strength due to the improvement of interfacial adhesion force. Better dispersibility and stronger interfacial bonding between MWCNTs and epoxy matrix by acid treatment and triethylene-tetramine (TETA) modification of multi-walled carbon nanotubes (MWCNTs). MWCNTs were treated with concentrated $\mathrm{H}_{2} \mathrm{SO}_{4} / \mathrm{HNO}_{3}$, and then triethylenetetramine (TETA) grafting showed formation of TETA thin layer on the MWCNT surface, which contributes to the homogenous dispersion of MWCNTs in epoxy matrix and the improvement of the MWCNT-epoxy interfacial interaction $^{[70,71]}$. Amino-functionalized MWNTs/epoxy nanocomposites, in which MWNTs with amino groups acted as a curing agent resulting in improvement of the tensile strength $(+51 \%)$ and impact strength $(+93 \%)$ is obtained with amine-treated MWNTs at an $1.5 \mathrm{wt}^{\circ} \%$ content $^{\left[{ }^{72]}\right]}$ and fracture toughness $K_{I C}$ turned out to be significantly increased (45\%) adding only $0.3 \%$ of amino-functionalised doublewalled carbon nanotubes (DWCNT-NH2) ${ }^{[73]}$. It was found that tetra-functional epoxy resin, MY-720 mixed with $1 \%$ by weight MWNT increased the fracture toughness of the neat resin by more than three folds in the three-point bend mode ${ }^{[74]}$. Catalytically grown double-wall carbon nanotubes (DWCNT) were used in epoxy resin and a very good dispersion of both DWCNTs and carbon black $(\mathrm{CB})$ in an epoxy resin could be observed with increased $K_{I C}$-value was observed ${ }^{[75]}$. Rahmat and Hubert ${ }^{[78]}$ in their review presented carbon nanotube-polymer interactions in nanocomposites and concluded that an optimum carbon nanotube-polymer interaction is a key factor towards reaching the full potential of carbon nanotubes in nanocomposites while presence of moisture absorption may cause degradation resulting in weak interfacial bonding due to epoxy swelling ${ }^{[79]}$ and it is known that nano-composite toughness increased with enhanced interfacial adhesion ${ }^{[80]}$. Multi-walled carbon nanotube reinforced epoxy nanocomposites, with multiwalled carbon nanotubes (MWCNTs) to diglycidyl ether of bisphenol-F epoxy via the ultrasonic technique resulted in a higher reinforcing efficiency and consequently, the cryogenic tensile strength, Young's modulus, failure strain and impact strength at $77 \mathrm{~K}$ are all enhanced ${ }^{[37]}$. Nanotube morphology and impurity content can significantly affect the effective properties of the resulting composite as found by Hernández-Pérez et al ${ }^{\left[{ }^{[1]}\right.}$. Nanotubes with different aspect ratios showed very limited improvement in tensile properties, where the impact resistance and fracture toughness of the nanocomposites were significantly improved, for the composites employing the nanotubes with higher aspect ratio ${ }^{[81]}$. Controlling curing process ${ }^{[82]}$, preventing agglomerate of nanotubes as large clumps of black powder ${ }^{[83]}$, purification of single-wall carbon nanotubes ${ }^{[84]}$ also help in proper dispersion resulting in enhanced properties of epoxy composites. The nanocomposites produced exhibited an enhanced strength and stiffness and significant increase in fracture toughness ( $43 \%$ ) at $0.5 \mathrm{wt} . \%$ amino-functionalised DWCNT addition ${ }^{[85]}$.

The outcome of multiphase study revealed great potential route that could be explored as established with the presence of liquid rubber. The addition of rubber increased Mode I fracture toughness by $409 \%$ in comparison with pristine epoxy. MWCNT is still the most interesting candidate with a promising outlook, by choosing an appropriate dispersion and functionalization techniques. Table 3 Summaries the published reports on CNTs-filled epoxies to evaluate the influence of these fillers on increasing fracture toughness.

\section{Hybrid Polymers Composites}

Hybrid polymer composites (HPC) are one of the recent developments to reduce the cost of expensive composites containing reinforcements like carbon fiber by incorporating a proportion of cheaper, low-quality fibers such as glass, textile, natural fibers, and nano figures like silica, rubber, CNT, clay, graphene. The concept of hybrid toughening refers to the use of two or more toughening agents to achieve some synergistic effect in the toughness of the overall nanocomposites ${ }^{[4]}$. Gouda et al.$^{[4]}$ investigated the fracture behavior of a high silica glass-satin textile fiber reinforced hybrid polymer composite (HPC) under the full range of in-plane loading conditions experimentally and numerically. The observation of fracture surface shows that the Mode I fracture surface is of brittle matrix cracking with relatively smooth flat matrix fracture and showed little debonding between fiber and matrix. Crack specimens are tough in tensile loading condition and weak in shear loading conditions. Tsai et al. ${ }^{[88]}$ investigated the interlaminar fracture toughness of glass fiber/epoxy composites having silica nanoparticles 


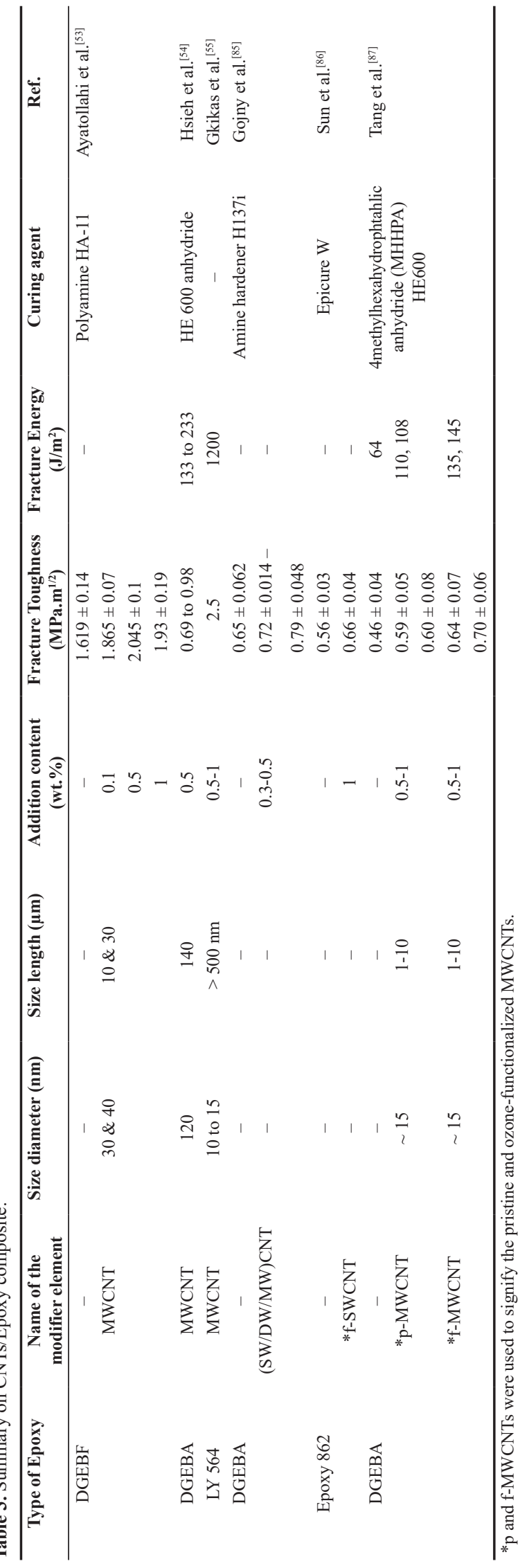


and the rubber particles. Reactive liquid rubber (CTBN) and core-shell rubber (CSR), were employed to modify the fracture toughness of epoxy resin. Silica nano particle increased the fracture toughness of the fiber composite with pure or CTBN-modified epoxy. The silica nanoparticle effect would become detrimental when the fiber composites are already modified by CSR. By considering the overall mechanical performances, the fiber composite with silica nanocomposites together with CTBN rubber particles demonstrate superior properties. Hsieh et al. ${ }^{[89]}$ presented the structure/property relationship of an anhydride-cured epoxy modified with silica nanoparticles and/or a rubber microparticle. Transmission electron micrographs of 'hybrid' epoxy polymers containing $2.3 \mathrm{wt} . \%$ silica nanoparticles and 9 wt.\% CTBN is shown in Figure 8.

The fracture energy of the bulk epoxy increased from 77 to $212 \mathrm{~J} / \mathrm{m}^{2}$ with $20 \mathrm{wt} . \%$ silica nanoparticles addition. The observed toughening mechanisms were debonding of the epoxy polymer from the silica nanoparticles, followed by plastic void growth of the epoxy. Localised plastic shear-banding in the polymer was also observed. Maximum fracture energy of $965 \mathrm{~J} / \mathrm{m}^{2}$ was measured for a 'hybrid' epoxy polymer containing 9 and $15 \mathrm{wt} . \%$ of the rubber microparticles and silica nanoparticles respectively. Both the theoretical and experimental studies clearly revealed the benefits of using silica nanoparticles, as opposed to much larger micrometre-sized silica particles, in terms of observing a relatively high toughness for the modified epoxy polymer. Although the toughness increase is dependent on the toughener used, its concentration and particle size, the second-phase materials have been shown of increasing the toughness of epoxy polymers. It should be noted that the toughening effect is also dependent on the properties of the epoxy itself, as some epoxies are tougher in nature than others ${ }^{[89]}$. Figure 9 shows evidence of cavitation of the rubber particles, though it is difficult to identify the mechanisms associated with the silica nanoparticles due to the roughness of the surfaces. However, SEM studies of the 'hybrid' fracture surfaces showed that the silica nanoparticles are present as both individual particles and agglomerates ${ }^{[89]}$.

Gouda et al. ${ }^{[00]}$ studied Mode I fracture behavior of glass-carbon fiber reinforced hybrid polymer composite experimentally and by finite element analysis at room temperature with curing hardener (HY 951) and woven glass and carbon bi-direction mesh. The difference in the magnitude of elastic modulus along and across the fiber orientation is $417 \mathrm{MPa}$. Mode I fracture surface is indicative of brittle cleavage failure with relatively smooth and flat matrix fracture with a little debonding between fiber and matrix. The fracture energy of hybrid carbon fiber reinforced polymers was investigated by Karapappas et al. ${ }^{[1]}$. The composites were modified by multi-walled carbon nanotubes addition in the matrix material. The interlaminar fracture properties under Mode I and Mode II remote loading were studied as a function of the carbon nanotube content in the matrix. Carbon nanotubes in the epoxy matrix led a significant increase in the load bearing ability as well as in the fracture energy, for both Mode I and Mode II tests. It is speculated that carbon nanotubes due to their large aspect ratio have a significant toughening effect since extra energy is needed in order to pull them out from the matrix and start the crack propagation following a

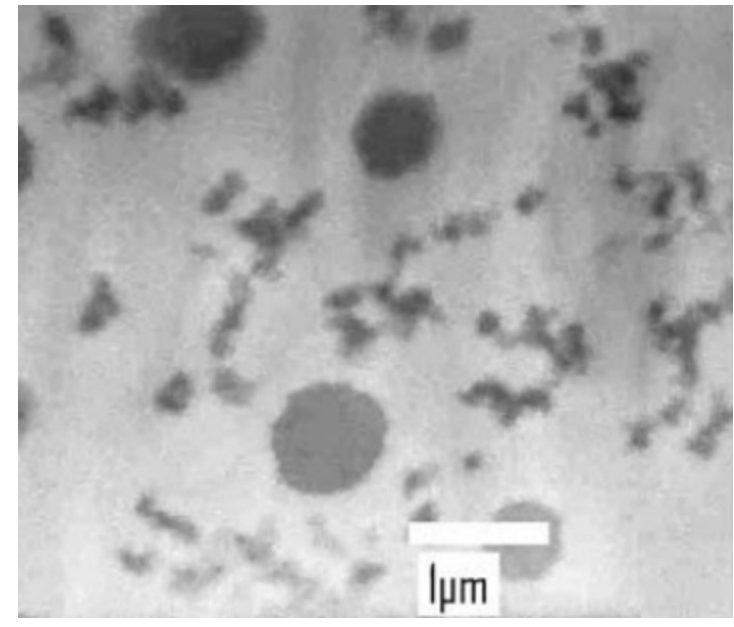

Figure 8. TEM image of 'hybrid' epoxy polymers containing 2.3 wt.\% silica nanoparticles and 9 wt.\% $\mathrm{CTBN}^{[18]}$.

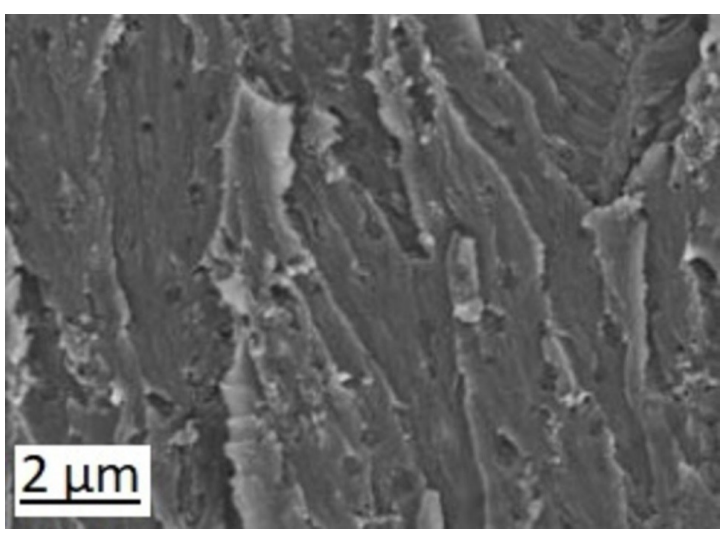

Figure 9. SEM image of fracture surface of epoxy polymers with 4.5 wt. $\%$ silica nanoparticles and 9 wt. $\% \mathrm{CTBN}^{[18]}$.

kinking out pattern at nano scale. Lee et al. ${ }^{[92]}$ investigated Mode I and Mode II interlaminar fracture toughness of the hybrid laminates with nonwoven carbon tissue (NWCT) under severe temperature conditions, the double cantilever beam (DCB) and end notched flexure (ENF) tests for the carbon fiber reinforced polymer (CFRP) and the hybrid specimens were conducted. The $G_{I C}$ and $G_{I I C}$ values of the hybrid laminates were compared with those of the CFRP laminates in the range of $-60^{\circ} \mathrm{C}$ to $+80^{\circ} \mathrm{C}$. The mean $G_{I C}$ values of the CFRP and hybrid specimens at $-60{ }^{\circ} \mathrm{C}$ and $-30^{\circ} \mathrm{C}$ were not changed significantly when compared with those the CFRP and hybrid specimens at room temperature. The mean $G_{I I C}$ values of the hybrid specimens at $-60{ }^{\circ} \mathrm{C}$ to $+80{ }^{\circ} \mathrm{C}$ were about $171 \%$ to $189 \%$ higher than those of the CFRP specimens at $-60{ }^{\circ} \mathrm{C}$ to $+80{ }^{\circ} \mathrm{C}$, respectively. When compared with the decreasing rate of the mean $G_{\text {IIC }}$ values of the CFRP specimens at $+80{ }^{\circ} \mathrm{C}$, the decreasing rate of the mean $G_{I I C}$ values of the hybrid specimens at $+80^{\circ} \mathrm{C}$ slowed down significantly due to the carbon shortfibers bridging, carbon short-fibers breakage and hackles. Borowski et al. ${ }^{[93]}$ investigated the fracture toughness of carbon fiber reinforced polymer (CFRP) laminates produced by using an epoxy nanocomposite matrix reinforced with 
Table 4. Summary on Hybrid Polymers Composites.

\begin{tabular}{|c|c|c|c|c|c|}
\hline Type of Fiber & $\begin{array}{c}\text { Name of the modifier } \\
\text { element }\end{array}$ & $\begin{array}{c}\% \text { of content } \\
\text { addition (wt. \%) }\end{array}$ & $\begin{array}{c}\% \text { of } K_{I C}, \text { MPa.m }^{1 / 2} \\
\text { increment }\end{array}$ & $\begin{array}{c}\% \text { of } G_{I C}, \mathbf{J} / \mathbf{m}^{2} \\
\text { increment }\end{array}$ & Ref. \\
\hline \multirow[t]{2}{*}{ High silica glass fiber } & Woven Satin textile fiber & $t=0.26 \mathrm{~mm}$ & $7.431\left[0^{\circ}\right]$ & - & Gouda et al. ${ }^{[4]}$ \\
\hline & & & $4.199\left[90^{\circ}\right]$ & & \\
\hline \multirow[t]{3}{*}{ *GFRP } & - & - & - & 190 & Tsai et al. ${ }^{[88]}$ \\
\hline & $\mathrm{SiO}_{2}-\mathrm{CTBN}$ & 10 wt. $\%$ each & - & 930 & \\
\hline & $\mathrm{SiO}_{2}-\mathrm{CSR}$ & 10 wt. $\%$ each & - & $1030(390 \%)$ & \\
\hline GFRP & Rubber $(\mu \mathrm{m})-\mathrm{SiO}_{2}(\mathrm{~nm})$ & 9 wt. $\%, 15$ wt. $\%$ & - & 965 & Hsieh et al. ${ }^{[89]}$ \\
\hline \multirow[t]{2}{*}{ GFRP } & Carbon & $0 / 90$ & 34.07 (Across) & - & Gouda et al. ${ }^{[90]}$ \\
\hline & & & 32.84 (Along) & & \\
\hline \multirow[t]{3}{*}{$*$ CFRP } & MWCNT & 0.1 & - & $200-300$ & Karapappas et al. ${ }^{[91]}$ \\
\hline & & 0.5 & - & $400-500$ & \\
\hline & & 1 & - & $400-600$ & \\
\hline \multirow[t]{4}{*}{ CFRP } & MWCNT & - & - & $943(442 \%)$ & Borowski et al. ${ }^{[93]}$ \\
\hline & & 0.5 & - & $1175(25 \%)$ & \\
\hline & & 1 & - & $1132(20 \%)$ & \\
\hline & & 1.5 & - & $1102(17 \%)$ & \\
\hline
\end{tabular}

*Glass fibre reinforced-polymer (GFRP) and carbon-fibre reinforced-polymer (CFRP).

carboxyl functionalized multi-walled carbon nanotubes (COOH-MWCNTs). Four MWCNTs contents of $0.0-$ $1.5 \%$ per weight of the epoxy resin/hardener mixture were examined. Double cantilever beam (DCB) tests performed to determine the Mode I interlaminar fracture toughness of the unidirectional CFRP composites showed 25\%, 20\%, and $17 \%$ increase in the maximum interlaminar fracture toughness of the CFRP composites. The involvement of silica and rubber particles in glass fiber epoxy has shown a major improvement in Mode I fracture toughness with lowered stiffness due to low modulus rubber particles as highlighted by Tsai et al. ${ }^{[88]}$. Study conducted by Hsieh et al. ${ }^{\left[{ }^{89]}\right.}$ reported maximum fracture energy of $965 \mathrm{~J} / \mathrm{m}^{2}$ for a hybrid polymer composite containing 9 wt. $\%$ and 15 wt. $\%$ of the rubber microparticles and silica nanoparticles, respectively. Karapappas et al. ${ }^{\left[{ }^{11]}\right.}$ and Borowski et al. ${ }^{[93]}$ has reported the increase in fracture toughness of hybrid carbon fiber reinforced polymers for low loading of Multi-walled carbon nanotubes. It was found that toughness of epoxy can be significantly increased by incorporating either rubber or silica nano-particles, however, hybrid nanocomposites do not display any significant effect on toughness ${ }^{[94]}$. Carolan et al. ${ }^{[95]}$ observed increase in toughness in the bulk epoxy polymer by the addition of a combination of silica nanoparticles and/or CSR nanoparticles. Rubbery and glassy epoxy resins reinforced with carbon nanotubes created a bridge between the nanotubes and matrix, and differences in viscosity resulted better nanotubes dispersion in the rubbery epoxy resin than in glassy epoxy with $28 \%$ increase in tensile Young's modulus in the rubbery system using 1 wt.\% functionalized nanotubes ${ }^{[76]}$. The values of toughness of the CFRP laminates, compared to the bulk epoxy polymer, were further enhanced by additional fibre-based toughening mechanisms, i.e., fibre bridging, fibre debonding and fibre pull-out. It was also observed that epoxy/acryl triblock copolymer alloys, applied as the toughening modifiers for the epoxy resins, rubbery epoxy particles successfully acted as toughening agent for glassy epoxy matrices ${ }^{[96-98]}$, effects of both rubbery phase and nanosilica on mechanical properties of epoxy showed that fracture surfaces were accompanied with multiple voids, providing evidence of debonding of the nanoparticles ${ }^{[99]}$. It has been well established that the incorporation of second soft microphase such as rubber particles into epoxy polymers increase their toughness, without significant impairing other properties whereas addition of nanosilica particles to rubber-toughened epoxy may lead to very significant increase in the toughness of the matrix ${ }^{[100]}$. Summarising, the effect of having multiphase in polymer composite is highly beneficial in order to attain good mechanical and fracture properties of polymer composite. Table 4 presents the summary of published reports on hybrid polymers composites.

It can be concluded from the present study that addition of a second dispersed phase (silica, rubber, CNTs) in epoxies results in enhancing the material fracture toughness and inducing a remarkable increase of damage tolerance performance.

\section{Conclusions}

In the research conducted so far, the fracture toughness of the epoxy based polymer matrix composite incorporating silica, rubber and CNTs in micro/nano sizes is and attempt is made to understand the controlling toughening mechanisms of these materials. Following are the major conclusions with proposed future direction:

(1) Silica addition promoted nano toughening effect with plastically deformation capability in epoxies. Addition of rubber increased the toughness with negligible reduction in stiffness in epoxies. Double and multi walled CNTs addition significantly increased the tensile properties; hardness, impact resistance and fracture toughness of epoxy resins;

(2) Summarising, the effect of having multiphase in polymer composite is highly beneficial in order to attain good mechanical and fracture properties of polymer composite;

(3) The advantages of using nanofillers modified epoxies as matrices or interleafs for carbon fiber and glass fiber 
composites to increase the interlaminar delamination toughness are not fully explored for better efficiency than some conventional methods;

(4) More emphasis can be laid on the crucial understanding of stress transfer mechanisms and interfacial bond strength between nanoparticles and the epoxy system and the fracture toughness of hybrid polymer composite under different temperature conditions needs to be elaborated;

(5) The experiments conducted so far to measure different modes of fracture toughness of hybrid nanocomposites may be numerical validated (modeling);

(6) In CNT modified epoxies, further studies are required to clarify the predominant toughening mechanisms with respect to the different $\mathrm{CNT}$ morphology although crack bridging is important.

\section{References}

1. Hsieh, T. H., Kinloch, A. J., Masania, K., Taylor, A. C., \& Sprenger, S. (2010). The mechanisms and mechanics of the toughening of epoxy polymers modified with silica nanoparticles. Polymer, 51(26), 6284-6294. http://dx.doi.org/10.1016/j. polymer.2010.10.048.

2. Bray, D. J., Dittanet, P., Guild, F. J., Kinloch, A. J., Masania, K., Pearson, R. A., \& Taylor, A. C. (2013). The modelling of the toughening of epoxy polymers via silica nanoparticles: the effects of volume fraction and particle size. Polymer, 54(26), 7022-7032. http://dx.doi.org/10.1016/j.polymer.2013.10.034.

3. Domun, N., Hadavinia, H., Zhang, T., Sainsbury, T., Liaghat, G. H., \& Vahid, S. (2015). Improving the fracture toughness and the strength of epoxy using nanomaterials: a review of the current status. Nanoscale, 7(23), 10294-10329. http://dx.doi. org/10.1039/C5NR01354B. PMid:26006766.

4. Gouda, P. S. S., Kodancha, K. G., Siddaramaiah \& Jawali, D. (2013). Experimental and numerical investigations on fracture behavior of high silica glass/satin textile fiber reinforced hybrid polymer composites. Advanced Materials Letters, 4(11), 827835. http://dx.doi.org/10.5185/amlett.2013.3450.

5. Day, R. J., Lovell, P. A., \& Wazzan, A. A. (2001). Toughened carbon/epoxy composites made by using core/shell particles. Composites Science and Technology, 61(1), 41-56. http://dx.doi. org/10.1016/S0266-3538(00)00169-X.

6. Zaroog, O. S., Zein, M. A. M., \& Manap, A. N. A. (2012). Fracture toughness of composite materials. International Journal of Scientific Research, 3(8), 1759-1766.

7. Marouf, B. T., Mai, Y.-W., Bagheri, R., \& Pearson, R. A. (2016). Toughening of epoxy nanocomposites: nano and hybrid effects. Polymer Reviews, 56(1), 70-112. http://dx.doi.org/10.1080/1 5583724.2015 .1086368$.

8. Dittanet, P., \& Pearson, R. A. (2012). Effect of silica nanoparticle size on toughening mechanisms of filled epoxy. Polymer, 53(9), 1890-1905. http://dx.doi.org/10.1016/j.polymer.2012.02.052.

9. Dittanet, P., \& Pearson, R. A. (2013). Effect of bimodal particle size distributions on the toughening mechanisms in silica nanoparticle filled epoxy resin. Polymer, 54(7), 1832-1845. http://dx.doi.org/10.1016/j.polymer.2012.12.059.

10. Johnsen, B. B., Kinloch, A. J., Mohammed, R. D., Taylor, A. C., \& Sprenger, S. (2007). Toughening mechanisms of nanoparticle-modified epoxy polymers. Polymer, 48(2), 530541. http://dx.doi.org/10.1016/j.polymer.2006.11.038.

11. Blackman, B. R. K., Kinloch, A. J., Sohn Lee, J., Taylor, A. C., Agarwal, R., Schueneman, G., \& Sprenger, S. (2007). The fracture and fatigue behaviour of nano-modified epoxy polymers. Journal of Materials Science, 42(16), 7049-7051. http://dx.doi.org/10.1007/s10853-007-1768-6.

12. Adachi, T., Osaki, M., Araki, W., \& Kwon, S.-C. (2008). Fracture toughness of nano- and micro-spherical silica-particle-filled epoxy composites. Acta Materialia, 56(9), 2101-2109. http:// dx.doi.org/10.1016/j.actamat.2008.01.002.

13. Kwon, S.-C., \& Adachi, T. (2007). Strength and fracture toughness of nano and micron-silica particles bidispersed epoxy composites: evaluated by fragility parameter. Journal of Materials Science, 42(14), 5516-5523. http://dx.doi.org/10.1007/ s10853-006-1025-4.

14. Adachi, T., Araki, W., Nakahara, T., Yamaji, A., \& Gamou, M. (2002). Fracture toughness of silica particulate-filled epoxy composite. Journal of Applied Polymer Science, 86(9), 22612265. http://dx.doi.org/10.1002/app.11206.

15. Roulin-Moloney, A. C., Cantwell, W. J., \& Kausch, H. H. (1987). Parameters determining the strength and toughness of particulate-filled epoxy resins. Polymer Composites, 8(5), 314-323. http://dx.doi.org/10.1002/pc.750080506.

16. Beaumont, P. W. R., \& Young, R. J. (1975). Failure of brittle polymers by slow crack growth. Journal of Materials Science, 10(8), 1334-1342. http://dx.doi.org/10.1007/BF00540823.

17. Nakamura, Y., Yamaguchi, M., Okubo, M., \& Matsumoto, T. (1992). Effect of particle size on the fracture toughness of epoxy resin filled with spherical silica. Polymer, 33(16), 3415-3426. http://dx.doi.org/10.1016/0032-3861(92)91099-N.

18. Nakamura, Y., Okabe, S., \& Iida, T. (1999). Effects of particle shape, size and interfacial adhesion on the fracture strength of silica-filled epoxy resin. Polymers \& Polymer Composites, 7, 177-186.

19. Cantwell, W. J., Roulin-Moloney, A. C., \& Kaiser, T. (1988). Fractography of unfilled and particulate-filled epoxy resins. Journal of Materials Science, 23(5), 1615-1631. http://dx.doi. org/10.1007/BF01115700.

20. Moloney, A. C., Kausch, H. H., \& Stieger, H. R. (1983). The fracture of particulate-filled epoxide resins. Journal of Materials Science, 18(1), 208-216. http://dx.doi.org/10.1007/ BF00543827.

21. Chen, C., Justice, R. S., Schaefer, D. W., \& Baur, J. W. (2008). Highly dispersed nanosilica-epoxy resins with enhanced mechanical properties. Polymer, 49(17), 3805-3815. http:// dx.doi.org/10.1016/j.polymer.2008.06.023.

22. Liang, Y. L., \& Pearson, R. A. (2009). Toughening mechanisms in epoxy-silica nanocomposites (ESNs). Polymer, 50(20), 4895-4905. http://dx.doi.org/10.1016/j.polymer.2009.08.014.

23. Ma, J., Mo, M.-S., Du, X.-S., Rosso, P., Friedrich, K., \& Kuan, H.-C. (2008). Effect of inorganic nanoparticles on mechanical property, fracture toughness and toughening mechanism of two epoxy systems. Polymer, 49(16), 3510-3523. http://dx.doi. org/10.1016/j.polymer.2008.05.043.

24. Zhang, H., Tang, L.-C., Zhang, Z., Friedrich, K., \& Sprenger, S. (2008). Fracture behaviours of in situ silica nanoparticle-filled epoxy at different temperatures. Polymer, 49(17), 3816-3825. http://dx.doi.org/10.1016/j.polymer.2008.06.040.

25. Rosso, P., Ye, L., Friedrich, K., \& Sprenger, S. (2006). A toughened epoxy resin by silica nanoparticle reinforcement. Journal of Applied Polymer Science, 100(3), 1849-1855. http:// dx.doi.org/10.1002/app.22805.

26. Zhang, H., Zhang, Z., Friedrich, K., \& Eger, C. (2006). Property improvements of in situ epoxy nanocomposites with reduced interparticle distance at high nanosilica content. Acta Materialia, 54(7), 1833-1842. http://dx.doi.org/10.1016/j. actamat.2005.12.009.

27. Ragosta, G., Abbate, M., Musto, P., Scarinzi, G., \& Mascia, L. (2005). Epoxy-silica particulate nanocomposites: chemical interactions, reinforcement and fracture toughness. 
Polymer, 46(23), 10506-10516. http://dx.doi.org/10.1016/j. polymer.2005.08.028.

28. Karger-Kocsis, J., Gryshchuk, O., Fröhlich, J., \& Mülhaupt, R. (2003). Interpenetrating vinylester/epoxy resins modified with organophilic layered silicates. Composites Science and Technology, 63(14), 2045-2054. http://dx.doi.org/10.1016/ S0266-3538(03)00110-6.

29. Fu, S.-Y., Feng, X.-Q., Lauke, B., \& Mai, Y.-W. (2008). Effects of particle size, particle/matrix interface adhesion and particle loading on mechanical properties of particulate-polymer composites. Composites. Part B, Engineering, 39(6), 933-961. http://dx.doi.org/10.1016/j.compositesb.2008.01.002.

30. Guo, Y., \& Li, Y. (2007). Quasi-static/dynamic response of SiO2-epoxy nanocomposites. Materials Science and Engineering A, 458(1-2), 330-335. http://dx.doi.org/10.1016/j. msea.2007.02.011.

31. Chikhi, N., Fellahi, S., \& Bakar, M. (2002). Modification of epoxy resin using reactive liquid (ATBN) rubber. European Polymer Journal, 38(2), 251-264. http://dx.doi.org/10.1016/ S0014-3057(01)00194-X.

32. Zhao, Y., Chen, Z.-K., Liu, Y., Xiao, H.-M., Feng, Q.-P., \& Fu, S.-Y. (2013). Simultaneously enhanced cryogenic tensile strength and fracture toughness of epoxy resins by carboxylic nitrile-butadiene nano-rubber. Composites. Part A, Applied Science and Manufacturing, 55, 178-187. http://dx.doi. org/10.1016/j.compositesa.2013.09.005.

33. Chen, J., \& Taylor, A. C. (2012). Epoxy modified with triblock copolymers: morphology, mechanical properties and fracture mechanisms. Journal of Materials Science, 47(11), 4546-4560. http://dx.doi.org/10.1007/s10853-012-6313-6.

34. Tang, L.-C., Zhang, H., Sprenger, S., Ye, L., \& Zhang, Z. (2012). Fracture mechanisms of epoxy-based ternary composites filled with rigid-soft particles. Composites Science and Technology, 72(5), 558-565. http://dx.doi.org/10.1016/j. compscitech.2011.12.015.

35. Jiang, T., Kuila, T., Kim, N. H., Ku, B.-C., \& Lee, J. H. (2013). Enhanced mechanical properties of silanized silica nanoparticle attached graphene oxide/epoxy composites. Composites Science and Technology, 79, 115-125. http://dx.doi.org/10.1016/j. compscitech.2013.02.018.

36. Yang, G., Zheng, B., Yang, J.-P., Xu, G.-S., \& Fu, S.-Y. (2008). Preparation and cryogenic mechanical properties of epoxy resins modified by poly(ethersulfone). Journal of Polymer Science. Part A, Polymer Chemistry, 46(2), 612-624. http:// dx.doi.org/10.1002/pola.22409.

37. Chen, Z.-K., Yang, J.-P., Ni, Q.-Q., Fu, S.-Y., \& Huang, Y.-G. (2009). Reinforcement of epoxy resins with multi-walled carbon nanotubes for enhancing cryogenic mechanical properties. Polymer, 50(19), 4753-4759. http://dx.doi.org/10.1016/j. polymer.2009.08.001.

38. Nishijima, S., Honda, Y., Tagawa, S., \& Okada, T. (1996). Study of epoxy resin for cryogenic use by positron annihilation method. Journal of Radioanalytical and Nuclear Chemistry, 211(1), 93-101. http://dx.doi.org/10.1007/BF02036260.

39. Yang, J.-P., Yang, G., Xu, G., \& Fu, S.-Y. (2007). Cryogenic mechanical behaviors of MMT/epoxy nanocomposites. Composites Science and Technology, 67(14), 2934-2940. http:// dx.doi.org/10.1016/j.compscitech.2007.05.012.

40. Yang, G., Fu, S.-Y., \& Yang, J.-P. (2007). Preparation and mechanical properties of modified epoxy resins with flexible diamines. Polymer, 48(1), 302-310. http://dx.doi.org/10.1016/j. polymer.2006.11.031.

41. Yahyaie, H., Ebrahimi, M., Tahami, H. V., \& Mafi, E. R. (2013). Toughening mechanisms of rubber modified thin film epoxy resins. Progress in Organic Coatings, 76(1), 286-292. http:// dx.doi.org/10.1016/j.porgcoat.2012.09.016.
42. Arias, M. L., Frontini, P. M., \& Williams, R. J. (2003). Analysis of the damage zone around the crack tip for two rubbermodified epoxy matrices exhibiting different toughenability. Polymer, 44(5), 1537-1546. http://dx.doi.org/10.1016/S00323861(02)00829-7.

43. Tripathi, G., \& Srivastava, D. (2007). Effect of carboxylterminated poly(butadiene-co-acrylonitrile) (CTBN) concentration on thermal and mechanical properties of binary blends of diglycidyl ether of bisphenol-A (DGEBA) epoxy resin. Materials Science and Engineering A, 443(1-2), 262-269. http://dx.doi.org/10.1016/j.msea.2006.09.031.

44. Huang, F., Liu, Y., Zhang, X., Wei, G., Gao, J., Song, Z., Zhang, M., \& Qiao, J. (2002). Effect of elastomeric nanoparticles on toughness and heat resistance of epoxy resins. Macromolecular Rapid Communications, 23(13), 786-790. http://dx.doi. org/10.1002/1521-3927(20020901)23:13<786::AIDMARC786>3.0.CO;2-T.

45. Pearson, R. A., \& Yee, A. F. (1989). Toughening mechanisms in elastomer-modified epoxies. Journal of Materials Science, 24(7), 2571-2580. http://dx.doi.org/10.1007/BF01174528.

46. Dadfar, M. R., \& Ghadami, F. (2013). Effect of rubber modification on fracture toughness properties of glass reinforced hot cured epoxy composites. Materials \& Design, 47, 16-20. http://dx.doi.org/10.1016/j.matdes.2012.12.035.

47. Hwang, J.-F., Manson, J. A., Hertzberg, R. W., Miller, G. A., \& Sperling, L. H. (1989). Structure-property relationships in rubber-toughened epoxies. Polymer Engineering and Science, 29(20), 1466-1476. http://dx.doi.org/10.1002/pen.760292008.

48. Verchere, D., Sautereau, H., Pascault, J. P., Moschiar, S. M., Riccardi, C. C., \& Williams, R. J. J. (1990). Rubber-modified epoxies. I. Influence of carboxyl-terminated butadiene-acrylonitrile random copolymers $(\mathrm{CTBN})$ on the polymerization and phase separation processes. Journal of Applied Polymer Science, 41(34), 467-485. http://dx.doi.org/10.1002/app.1990.070410303.

49. Verchere, D., Pascault, J. P., Sautereau, H., Moschiar, S. M., Riccardi, C. C., \& Williams, R. J. J. (1991). Rubber-Modified epoxies. IV. Influence of morphology on mechanical properties. Journal of Applied Polymer Science, 43(2), 293-304. http:// dx.doi.org/10.1002/app.1991.070430208.

50. Tripathy, R., Ojha, U., \& Faust, R. (2011). Polyisobutylene modified bisphenol a diglycidyl ether based epoxy resins possessing improved mechanical properties. Macromolecules, 44(17), 6800-6809. http://dx.doi.org/10.1021/ma201081y.

51. Thomas, R., Yumei, D., Yuelong, H., Le, Y., Moldenaers, P., Weimin, Y., Czigany, T., \& Thomas, S. (2008). Miscibility, morphology, thermal, and mechanical properties of a DGEBA based epoxy resin toughened with a liquid rubber. Polymer, 49(1), 278-294. http://dx.doi.org/10.1016/j.polymer.2007.11.030.

52. Marouf, B. T. (2009). Effect of microstructure factors on fracture behavior of clay-rubber-epoxy hybrid nanocomposites (Doctoral thesis). Sharif University of Technology, Persian.

53. Ayatollahi, M. R., Shadlou, S., \& Shokrieh, M. M. (2011). Fracture toughness of epoxy/multi-walled carbon nanotube nano-composites under bending and shear loading conditions. Materials \& Design, 32(4), 2115-2124. http://dx.doi.org/10.1016/j. matdes.2010.11.034.

54. Hsieh, T. H., Kinloch, A. J., Taylor, A. C., \& Kinloch, I. A. (2011). The effect of carbon nanotubes on the fracture toughness and fatigue performance of a thermosetting epoxy polymer. Journal of Materials Science, 46(23), 7525-7535. http://dx.doi. org/10.1007/s10853-011-5724-0.

55. Gkikas, G., Barkoula, N.-M., \& Paipetis, A. S. (2012). Effect of dispersion conditions on the thermo-mechanical and toughness properties of multi walled carbon nanotubes-reinforced epoxy. Composites. Part B, Engineering, 43(6), 2697-2705. http:// dx.doi.org/10.1016/j.compositesb.2012.01.070. 
56. Yu, N., Zhang, Z. H., \& He, S. Y. (2008). Fracture toughness and fatigue life of MWCNT/epoxy composites. Materials Science and Engineering A, 494(1-2), 380-384. http://dx.doi. org/10.1016/j.msea.2008.04.051.

57. Gómez-del Río, T., Rodríguez, J., \& Pearson, R. A. (2014). Compressive properties of nanoparticle modified epoxy resin at different strain rates. Composites. Part B, Engineering, 57, 173-179. http://dx.doi.org/10.1016/j.compositesb.2013.10.002.

58. Fereidoon, A., Rajabpour, M., \& Hemmatian, H. (2013). Fracture analysis of epoxy/SWCNT nanocomposite based on global-local finite element model. Composites. Part B, Engineering, 54, 400-408. http://dx.doi.org/10.1016/j.compositesb.2013.05.020.

59. Spitalsky, Z., Tasis, D., Papagelis, K., \& Galiotis, C. (2010). Carbon nanotube-polymer composites: Chemistry, processing, mechanical and electrical properties. Progress in Polymer Science, 35(3), 357-401. http://dx.doi.org/10.1016/j. progpolymsci.2009.09.003.

60. Byrne, M. T., \& Gun'ko, Y. K. (2010). Recent advances in research on carbon nanotube-polymer composites. Advanced Materials, 22(15), 1672-1688. http://dx.doi.org/10.1002/ adma.200901545. PMid:20496401.

61. Chou, T.-W., Gao, L., Thostenson, E. T., Zhang, Z., \& Byun, J.-H. (2010). An assessment of the science and technology of carbon nanotube-based fibers and composites. Composites Science and Technology, 70(1), 1-19. http://dx.doi.org/10.1016/j. compscitech.2009.10.004.

62. Wichmann, M. H. G., Schulte, K., \& Wagner, H. D. (2008). On nanocomposite toughness. Composites Science and Technology, 68(1), 329-331. http://dx.doi.org/10.1016/j. compscitech.2007.06.027.

63. Guzmán de Villoria, R., \& Miravete, A. (2007). Mechanical model to evaluate the effect of the dispersion in nanocomposites. Acta Materialia, 55(9), 3025-3031. http://dx.doi.org/10.1016/j. actamat.2007.01.007.

64. Lau, K., Gu, C., \& Hui, D. (2006). A critical review on nanotube and nanotube/nanoclay related polymer composite materials. Composites. Part B, Engineering, 37(6), 425-436. http://dx.doi. org/10.1016/j.compositesb.2006.02.020.

65. Moniruzzaman, M., \& Winey, K. I. (2006). Polymer nanocomposites containing carbon nanotubes. Macromolecules, 39(16), 5194-5205. http://dx.doi.org/10.1021/ma060733p.

66. Gojny, F. H., Wichmann, M. H. G., Fiedler, B., Bauhofer, W., \& Schulte, K. (2005). Influence of nano-modification on the mechanical and electrical properties of conventional fibre-reinforced composites. Composites. Part A, Applied Science and Manufacturing, 36(11), 1525-1535. http://dx.doi. org/10.1016/j.compositesa.2005.02.007.

67. Xie, X., Mai, Y., \& Zhou, X. (2005). Dispersion and alignment of carbon nanotubes in polymer matrix: a review. Materials Science and Engineering R Reports, 49(4), 89-112. http:// dx.doi.org/10.1016/j.mser.2005.04.002.

68. Guo, P., Chen, X., Gao, X., Song, H., \& Shen, H. (2007). Fabrication and mechanical properties of well-dispersed multiwalled carbon nanotubes/epoxy composites. Composites Science and Technology, 67(15-16), 3331-3337. http://dx.doi. org/10.1016/j.compscitech.2007.03.026.

69. Park, S.-J., Jeong, H.-J., \& Nah, C. (2004). A study of oxyfluorination of multi-walled carbon nanotubes on mechanical interfacial properties of epoxy matrix nanocomposites. Materials Science and Engineering A, 385(1-2), 13-16. http://dx.doi. org/10.1016/j.msea.2004.03.041.

70. Li, S., Wang, F., Wang, Y., Wang, J., Ma, J., \& Xiao, J. (2008). Effect of acid and TETA modification on mechanical properties of MWCNTs/epoxy composites. Journal of Materials Science, 43(8), 2653-2658. http://dx.doi.org/10.1007/s10853-008-2489-1.
71. Yang, K., Gu, M., Guo, Y., Pan, X., \& Mu, G. (2009). Effects of carbon nanotube functionalization on the mechanical and thermal properties of epoxy composites. Carbon, 47(7), 17231737. http://dx.doi.org/10.1016/j.carbon.2009.02.029.

72. Chen, X., Wang, J., Lin, M., Zhong, W., Feng, T., Chen, X., Chen, J., \& Xue, F. (2008). Mechanical and thermal properties of epoxy nanocomposites reinforced with amino-functionalized multi-walled carbon nanotubes. Materials Science and Engineering A, 492(1-2), 236-242. http://dx.doi.org/10.1016/j. msea.2008.04.044.

73. Fiedler, B., Gojny, F. H., Wichmann, M. H. G., Nolte, M. C. M., $\&$ Schulte, K. (2006). Fundamental aspects of nano-reinforced composites. Composites Science and Technology, 66(16), 31153125. http://dx.doi.org/10.1016/j.compscitech.2005.01.014.

74. Ganguli, S., Bhuyan, M., Allie, L., \& Aglan, H. (2005). Effect of multi-walled carbon nanotube reinforcement on the fracture behavior of a tetrafunctional epoxy. Journal of Materials Science, 40(13), 3593-3595. http://dx.doi.org/10.1007/s10853005-2891-x.

75. Gojny, F. H., Wichmann, M. H. G., Köpke, U., Fiedler, B., \& Schulte, K. (2004). Carbon nanotube-reinforced epoxycomposites: enhanced stiffness and fracture toughness at low nanotube content. Composites Science and Technology, 64(15), 2363-2371. http://dx.doi.org/10.1016/j.compscitech.2004.04.002.

76. Liu, L., \& Wagner, H. D. (2005). Rubbery and glassy epoxy resins reinforced with carbon nanotubes. Composites Science and Technology, 65(11-12), 1861-1868. http://dx.doi.org/10.1016/j. compscitech.2005.04.002.

77. Rana, S., Alagirusamy, R., \& Joshi, M. (2009). A review on carbon epoxy nanocomposites. Journal of Reinforced Plastics and Composites, 28(4), 461-487. http://dx.doi. org/10.1177/0731684407085417.

78. Rahmat, M., \& Hubert, P. (2011). Carbon nanotube-polymer interactions in nanocomposites: a review. Composites Science and Technology, 72(1), 72-84. http://dx.doi.org/10.1016/j. compscitech.2011.10.002.

79. Lee, J. H., Rhee, K. Y., \& Lee, J. H. (2010). Effects of moisture absorption and surface modification using 3-aminopropyltriethoxysilane on the tensile and fracture characteristics of MWCNT/epoxy nanocomposites. Applied Surface Science, 256(24), 7658-7667. http://dx.doi.org/10.1016/j. apsusc.2010.06.023.

80. Lachman, N., \& Daniel Wagner, H. (2010). Correlation between interfacial molecular structure and mechanics in CNT/epoxy nano-composites. Composites. Part A, Applied Science and Manufacturing, 41(9), 1093-1098. http://dx.doi.org/10.1016/j. compositesa.2009.08.023.

81. Hernández-Pérez, A., Avilés, F., May-Pat, A., ValadezGonzález, A., Herrera-Franco, P. J., \& Bartolo-Pérez, P. (2008). Effective properties of multiwalled carbon nanotube/epoxy composites using two different tubes. Composites Science and Technology, 68(6), 1422-1431. http://dx.doi.org/10.1016/j. compscitech.2007.11.001.

82. Ci, L., \& Bai, J. (2006). The reinforcement role of carbon nanotubes in epoxy composites with different matrix stiffness. Composites Science and Technology, 66(3-4), 599-603. http:// dx.doi.org/10.1016/j.compscitech.2005.05.020.

83. Thostenson, E. T., \& Chou, T.-W. (2006). Processing-structuremulti-functional property relationship in carbon nanotube/ epoxy composites. Carbon, 44(14), 3022-3029. http://dx.doi. org/10.1016/j.carbon.2006.05.014.

84. Shelimov, K. B., Esenaliev, R. O., Rinzler, A. G., Huffman, C. B., \& Smalley, R. E. (1998). Purification of single-wall carbon nanotubes by ultrasonically assisted filtration. Chemical Physics Letters, 282(5-6), 429-434. http://dx.doi.org/10.1016/ S0009-2614(97)01265-7. 
85. Gojny, F., Wichmann, M., Fiedler, B., \& Schulte, K. (2005). Influence of different carbon nanotubes on the mechanical properties of epoxy matrix composites - A comparative study. Composites Science and Technology, 65(15-16), 2300-2313. http://dx.doi.org/10.1016/j.compscitech.2005.04.021.

86. Sun, L., Warren, G. L., O’Reilly, J. Y., Everett, W. N., Lee, S. M., Davis, D., Lagoudas, D., \& Sue, H.-J. (2008). Mechanical properties of surface-functionalized SWCNT/ epoxy composites. Carbon, 46(2), 320-328. http://dx.doi. org/10.1016/j.carbon.2007.11.051.

87. Tang, L., Zhang, H., Han, J., Wu, X., \& Zhang, Z. (2011). Fracture mechanisms of epoxy filled with ozone functionalized multi-wall carbon nanotubes. Composites, 72(1), 7-13. http:// dx.doi.org/10.1016/j.compscitech.2011.07.016.

88. Tsai, J.-L., Huang, B.-H., \& Cheng, Y.-L. (2009). Enhancing fracture toughness of glass/epoxy composites by using rubber particles together with silica nanoparticles. Journal of Composite Materials, 43(25), 3107-3123. http://dx.doi. org/10.1177/0021998309345299.

89. Hsieh, T. H., Kinloch, A. J., Masania, K., Sohn Lee, J., Taylor, A. C., \& Sprenger, S. (2010). The toughness of epoxy polymers and fibre composites modified with rubber microparticles and silica nanoparticles. Journal of Materials Science, 45(5), 1193-1210. http://dx.doi.org/10.1007/s10853-009-4064-9.

90. Gouda, P. S. S., Kudari, S. K., Prabhuswamy, S., \& Jawali, D. (2011). Fracture toughness of glass-carbon (0/90)s fiber reinforced polymer composite-an experimental and numerical study. Journal of Materials and Materials Characterization \& Engineering, 10, 671-682.

91. Karapappas, P., Vavouliotis, A., Tsotra, P., Kostopoulos, V., $\&$ Paipetis, A. (2009). Enhanced fracture properties of carbon reinforced composites by the addition of multi-wall carbon nanotubes. Journal of Composite Materials, 43(9), 977-985. http://dx.doi.org/10.1177/0021998308097735.

92. Lee, S.-H., Jeong, J.-S., Lee, Y.-S., \& Cheong, S. K. (2013). Interlaminar fracture toughness characteristics of hybrid laminates with nonwoven carbon tissue under severe temperature conditions. Journal of Composite Materials, 47(15), 1865-1875. http://dx.doi.org/10.1177/0021998312451864.
93. Borowski, E., Soliman, E., Kandil, U., \& Taha, M. (2015). Interlaminar fracture toughness of CFRP Laminates incorporating multi-walled carbon nanotubes. Polymers, 7(6), 1020-1045. http://dx.doi.org/10.3390/polym7061020.

94. Liu, H.-Y., Wang, G.-T., Mai, Y.-W., \& Zeng, Y. (2011). On fracture toughness of nano-particle modified epoxy. Composites. Part B, Engineering, 42(8), 2170-2175. http:// dx.doi.org/10.1016/j.compositesb.2011.05.014.

95. Carolan, D., Kinloch, A. J., Ivankovic, A., Sprenger, S., \& Taylor, A. C. (2016). Mechanical and fracture performance of carbon fibre reinforced composites with nanoparticle modified matrices. Procedia Structural Integrity, 2, 96-103. http://dx.doi. org/10.1016/j.prostr.2016.06.013.

96. Kishi, H., Kunimitsu, Y., Imade, J., Oshita, S., Morishita, Y., \& Asada, M. (2011). Nano-phase structures and mechanical properties of epoxy/acryl triblock copolymer alloys. Polymer, 52(3), 760-768. http://dx.doi.org/10.1016/j.polymer.2010.12.025.

97. Jansen, B. J. P., Tamminga, K. Y., Meijer, H. E. H., \& Lemstra, P. J. (1999). Preparation of thermoset rubbery epoxy particles as novel toughening modifiers for glassy epoxy resins. Polymer, 40(20), 5601-5607. http://dx.doi.org/10.1016/S00323861(98)00774-5.

98. Oldak, R. K., Hydro, R. M., \& Pearson, R. A. (2007). On the use of triblock copolymers as toughening agents for epoxies. Tampa: Adhesion Society.

99. Shayegan, M., \& Bagheri, R. (2010). The simultaneous effect of silica nanoparticles and rubber particles on the toughness of epoxy polymer. International Journal of Nanomanufacturing, 5(3/4), 232. http://dx.doi.org/10.1504/ IJNM.2010.033865.

100.Kim, H. S., \& Ma, P. (1996). Correlation between stress-whitening and fracture toughness in rubber-modified epoxies. Journal of Applied Polymer Science, 61(4), 659-662. http://dx.doi.org/10.1002/(SICI)10974628(19960725)61:4<659::AID-APP9>3.0.CO;2-K.

Received: May 21, 2020

Revised: Aug. 01, 2020

Accepted: Sept. 01, 2020 